\title{
Right Approach, Wrong Implications: A Critique of McKean on Products Liability
}

\author{
Guido Calabresi \\ Kenneth C. Bass III
}

I have very little argument with the basic framework which Professor McKean presents. ${ }^{1}$ Indeed, if one allows for the limitations on the detail possible in a paper, the framework in many respects closely parallels parts of the framework which $I$ have been using independently and which is partially set out in an article in the Journal of Law and Contemporary Problems ${ }^{2}$ and more fully in a recent book. ${ }^{3}$

The problems I have are more with the conclusions toward which Professor McKean tends. I say tends because at many points he makes clear that different goals would justify different results, and that, even accepting the goal of economic efficiency, one can "logically" defend systems of liability different from those which he seems to prefer. Yet once he has said this it seems quite clear that he believes that, to the extent economic efficiency is the goal, a system of consumer liability is likely to be best, except where producer fault or something which he feels is close to it can be shown.

$\dagger$ Professor of Law, Yale University.

¥ A.B. 1965, Duke University; LL.B. 1969, Yale University.

1 This paper was jointly written by Kenneth Bass and Guido Calabresi. Because there are citations to other writings of Calabresi and because it would seem awkward to refer to those in the third person, we have preferred to use the first person singular in this paper.

Our comments were written as a critique of the paper Professor McKean delivered at a conference sponsored by the Joint AEA-AALS (American Economic Association and Association of American Law Schools) Committee in March, 1969. McKean has since updated his paper and while he has not explicitly revised it to meet the criticisms there made, some changes in emphasis inevitably occurred. As a result, we feel that some of our criticisms were perhaps more appropriate to the original version than they are to the current version. Rather than revise our paper, however, we have preferred to leave it essentially in its original form and apologize to Professor McKean if some of the criticisms seem stronger than is justified.

2 Calabresi, Does the Fault System Optimally Control Primary Accident Costs?, 33 LAw \& Contrmp. Prob. 429 (1968). This article, which was not available to McKean when he originally wrote his paper, criticizes the fault system as a method of controlling primary accident costs.

3 G. Calabrest, The Costs of Accidents: A Legal and Economic Analysis (1970). This book was not available when McKean's paper was being prepared. 
This inclination I believe to be totally unwarranted by the goal of economic efficiency. Its general defense is made possible only (I) by an analysis which is insufficiently detailed in considering what transaction costs in practice are likely to make consumers or producers what I call the cheapest accident cost avoiders (McKean would say those who have a comparative advantage in preventing accidents ${ }^{4}$ ) and (2) by treating all products liability situations as if they were essentially the same, while in reality they differ precisely in factors which affect the relative ease with which a consumer or producer can avoid accident costs.

Most of my critique will be devoted to this point. I shall not, however, talk specifically about the disadvantages of using fault as a standard, as I would merely be repeating much of what I said in the article in the Journal of Law and Contemporary Problems. Before I take it further, however, I would like to make one general comment about McKean's framework.

Professor McKean writes as if we had two goals: economic efficiency (which is fairly traditional resource allocation) and fairness or equity (which encompasses all else). There is nothing logically wrong with using such a framework. But it does have certain practical disadvantages which are seen best by considering how McKean treats the issues of accident cost spreading and of the deep pocket (what I call the problem of secondary accident costs). To McKean these are entirely questions of what income distribution we want and simply an aspect of fairness or equity. ${ }^{5}$ In fact, most of the problems of secondary accident costs are due as much to the rapid changes in wealth which would result from unspread accident losses, as to the general degree of income disparity which exists in a society. As a result, many of the solutions (like negative income taxes) designed for income disparity would do very little to alleviate the economic and social dislocations which flow from unspread accident costs. This in itself would argue for treating them separately from more general income distribution problems.

More important, however, even though diminution of these secondary accident costs almost invariably entails some interpersonal comparisons of utility and hence is not amenable to the kind of economic efficiency analysis which McKean uses, it involves a discussion of alternatives which are far more concrete than those we usually relegate

4 It should actually be "comparative advantage in reducing accident costs." McKean does not explicitly discuss the difference, but he clearly recognizes that the concern of economic efficiency is to minimize the sum of accident losses and accident avoidance costs.

6 See, e.g., Mckean text preceding notes 102-03. 
to the catch-all of justice or fairness. Not as economists perhaps, but as lawyers, we today say with as much assurance as lawyers ever need that economic and social dislocations resulting from an accident are lessened if accident costs are spread widely or, to some extent, if they are borne by the wealthy. And when we say this we may be speaking of fairly objective items such as the degree of rehabilitation which occurs if losses are spread as against the cost of not having rehabilitation, as well as of more subjective items like the degree of loss one man feels at losing $\$ 10,000$ as against the degree of loss 10,000 men would feel from losing $\$ 1.00$ each.

Thus secondary accident cost avoidance is to some extent an alternative to economic efficiency (what I elsewhere call the general or market deterrence method of primary cost avoidance). We do indeed trade off, as McKean suggests, some economic efficiency for spreading ${ }^{6}$ and vice versa; but we do this because in a peculiar way we believe we are comparing costs and not, as McKean says, because we are willing to give up some "fairness" for economic efficiency. Indeed, most linguistic philosophers would object to the very use of the word fairness in a trade-off situation, seeing it as a minimum test all legal decisions must pass in the end rather than a subject of negotiation. I need not go into the uses to which the words fairness or justice can properly be put. It is enough for this critique to suggest that if we treat the secondary social and economic costs of accidents together with more general concepts of what is just, we make it much harder to analyze the main sources of secondary accident costs, and to discuss what can be done to lessen such costs most consistently with optimal resource allocation. In other words, we are likely to make those tradeoffs we cannot avoid more costly than they need to be.

My main problem with McKean's paper does not, however, come from these questions. It stems from the incomplete picture I feel he gives of how we should go about allocating accident costs even assuming economic efficiency to be our goal. ${ }^{7}$ Like McKean, I start from the

8 McKean text accompanying note 3 .

7 The bulk of this critique, therefore, ignores those situations where for a variety of reasons we prefer to make collective rather than market decisions as to how many accident costs as against accident avoidance costs we want. Discussion of this collective choice (which I call specific deterrence) and its relationship to the market choices we will make is an essential ingredient of any complete analysis of products liability situations. And it is not satisfactory to treat the occasions when we make collective determinations as justice or fairness trade-offs of the economic efficiency goal, as McKean seems to. Again, logically one could, but again, analytically one ought not. The reasons for collective interventions are often much more specific than what we usually term justice requirements. Indeed, they often are based on a judgment that we can accomplish more efficiently by collective fiat what the market would seek to accomplish but only in a more costly way. 
premise that were it not for transaction costs it would not matter from the standpoint of economic efficiency who bears the cost of any accident. While the premise is not new, it is crucial and deserves constant attention. It is the existence of transaction costs which makes it imperative that initial liability be placed on the party or combination of parties that can avoid accident costs most cheaply.

The existence of large transaction costs is obvious in products liability situations where "third parties" are injured. The cost of gathering all pedestrians who might be injured by an "unsafe car" or an "unsafe driver" and getting them to agree to bribe the car makers to make safer cars or drivers to drive more carefully is both obvious and enormous. The importance of burdening the party who can avoid accidents most cheaply when the choice is between an injured third party on the one hand and drivers or car makers on the other thus needs no demonstration.

It is not at first glance equally obvious that it is important to make a correct choice where the injury is to the buyer or seller in a products liability situation. ${ }^{8}$ What are the transaction costs here? Why will not buyers-if made to bear the burden-impose lower prices on sellers of unsafe products? Conversely, why will not sellers-if made to bear the burden-impose higher prices on unsafe users? Unlike many who have written in this area, McKean recognizes that transaction costs are, in fact, very significant even in these so-called bargaining cases. It is worthwhile analyzing these costs in more detail than he does, however, since such an analysis will help us understand which party in any specific bargaining situation is likely to be the cheapest avoider of accident costs.

The transaction costs which attach to a bargaining situation, and hence to most products liability cases, are generally those of differentiation and risk awareness. If liability is placed on auto manufacturers, we encourage (make cheaper) all those decisions which involve comparing the cost of making safer cars with the accident costs which might be avoided by having the safer cars. Conversely, we make more expensive all those decisions which involve a comparison of the cost of alter-

See Calabresi, supra note 2 , at $455,458 \&$ n.44. For these reasons, a complete analysis would treat collective or specific deterrence as a separate head from both justice and market deterrence, just as it would treat secondary costs as a separate head. Only after analyzing each of them separately would it attempt to combine them to reach policy conclusions. See generally CALABRESI, supra note 3.

8 I say buyer or seller because while the buyer is normally the initially injured party in a product liability situation, a liability rule that makes sellers strictly liable in effect makes the seller the injured party. I wish to emphasize that it is the liability rule we choose and not fate which determines who in the first instance bears the financial burden of the accident. See note 10 infra. 
ing driver behavior with the accident costs such changes in behavior would avoid. The reverse is true if we burden drivers. In theory, the car maker could, if held liable, charge different prices to drivers according to their accident proneness. But the cost of distinguishing drivers by accident proneness and enforcing differential prices is likely to be great enough so that car makers will find this an unsatisfactory way of lessening the burden; they are more likely instead to concentrate on making safer cars. Conversely, in theory also, drivers burdened with accident costs could demand lower prices from makers of relatively unsafe cars. But here too the information costs are likely to be too great to lead to much market pressure for safer cars, and the main thrust of the imposition of losses on drivers will be, if anywhere, on driver behavior. ${ }^{\circ}$

I do not mean to suggest that no pressure will exist on car makers if drivers are burdened, or on drivers if car makers are held liable. The most significant sub-categories of each activity might still be reached despite the transaction costs. For example, if car makers were liable, it might be worthwhile to sell cars at a different price to families with teen-age sons. And with driver liability, really unsafe cars might not be bought except at a discount. But this does not change the fact that transaction costs make it impossible to make all the distinctions we would in theory want to make. In other words, they make it essential that we put the burden on the party or parties which if burdened will be able to make the most important distinctions and choices, that is, the party with the greatest comparative advantage in safety. They also make it likely that we will supplement the market with collective regulations to control driver behavior if we burden the car makers, and car making if we burden drivers, but more on that later.

Up to this point then, I essentially agree with Professor McKean. It is when he starts discussing who is likely to have the comparative advantage in safety that we disagree. We part company because his suggestions as to the advantages of fault liability, customer liability without fault and absolute manufacturer liability suffer both from the overgeneralization and the insufficient analysis for which he criticizes

9 To demonstrate more clearly how different liability rules can give rise to costs which hinder efficient allocation, it is helpful to consider two specific examples. If manufacturers were held liable and they found that the most efficient way to reduce accident costs was to charge different prices to different consumers, they would face costs imposed by the Robinson-Patman Act. To prove the price differentials were not discriminatory and illegal, manufacturers would need to conduct extensive market research, keep detailed records and defend themselves in court. On the other hand, if consumers bore the initial risk of accident losses they would face substantial information costs in evaluating the comparative safety of different products. Similar information costs would also confront a manufacturer who sought to persuade consumers that his product was a safer substitute. 
the previous writers in the field.10 On the one hand, he takes a view from the mountain top and talks as if all product liability situations were the same in terms of the comparative advantage of users and sellers in producing safety. On the other hand, he becomes immersed in the trees and talks as if the party on whom the law initially puts the burden of an accident is the party who will ultimately bear the burden and hence will be the party who will make the decisions for or against a safer but potentially more expensive alternative. The usual case, either with or without insurance, is quite different.

I will discuss the second error first and in doing so will set out very briefly the guidelines ${ }^{\text {II }}$ for finding the party with a comparative advantage in safety. I will then use these to indicate how very different various products liability situations are from one another.

The search for the cheapest cost avoider begins with a rough guess as to the relative ease with which all the parties can avoid any given category of accidents, that is, minimize the sum of accident losses and accident avoidance costs. While traditional tort concepts restrict any such inquiry to the few parties most intimately involved in the accident, rough guesses should be made on an initial consideration of all possible parties. It is possible that the state has the cheapest opportunity to minimize automobile accident costs by building better roads and that allocation of costs to drivers or manufacturers, rather than to highway departments, results in less than cheapest cost avoidance. Rough guesses should thus operate primarily to exclude from further consideration those parties who seem to have minimal opportunity to reduce accident costs cheaply, but the exclusion process should begin with a constellation of possible loss bearers far larger than the few parties most closely connected with the accident.

The next step is a refinement of the rough guess. Crucial to this refinement is awareness of the possible externalization of the burden from the parties initially held liable to parties who have already been excluded on the basis of our rough guesses. For example, it is possible to conclude at the rough guess level that drivers and pedestrians both have a comparative advantage in minimizing the costs of driver-pedes-

10 I use the terms "liability" and "held liable" as in previous articles.

I am using the term to identify the party who under the law bears the initial undivided loss, whether that party is the party who is originally injured or the party who through a legal judgment must compensate the injured party and thereby becomes the financially injured party. I use the term this way to emphasize the fact that whether the originally injured party or some other party is made to bear the undivided loss, in the first instance, is the result of a legal judgment, a "holding liable," and not of metaphysics.

Calabresi, Fault, Accidents and the Wonderful World of Blum and Kalven, 75 Y YLE L.J. 216, 227 n.23 (1965).

11 These guidelines are described in full in CArABrEst, supra note 3, at 135-73. 
trian accidents compared to the society as a whole. It would be better to put the costs of such accidents on either of these parties or some combination rather than to have the general public bear the expense through public or private social insurance. Refining the analysis, it is possible that as between drivers and pedestrians the individual walker has a considerable comparative advantage. Thus, if we could make him pay a price equivalent to the cost to society of his failing to look, it might be far cheaper for him to "look both ways" than it would be if drivers bore the burden of accident costs and were thus induced to install pedestrian-finding radar in cars. If, however, we are content at this point to place liability on pedestrians, we might make a serious mistake as a result of externalization.

Were we to adopt a liability system which placed the costs of driverpedestrian accidents on pedestrians, the matter would not end there. Pedestrians would seek to obtain insurance and the insurance industry might find it very expensive to develop categories of walkers which were based on their accident proneness. As a result they might offer only one policy of comprehensive pedestrian accident insurance. Worse still, because walking is not an organized activity, insurance protection might be economically feasible only as part of a general "all accident" policy. This would effectively make the cost of car-pedestrian accidents a general cost of living rather than of walking. And putting car-pedestrian accident costs on living generally would mean placing the costs on an activity that has a far smaller comparative advantage in safety than does driving.

Nor might externalization be avoided by forbidding insurance by pedestrians. ${ }^{12}$ If pedestrians who are not insured consistently undervalue the risk involved in failing to look both ways, a very inadequate pressure to reduce accident costs might result-indeed, a less adequate pressure than if insured drivers were held liable. ${ }^{13}$

12 I am not here concerned with the secondary accident costs and fairness effects of barring insurance, though they are significant.

13 It might at first glance appear that when the party who bears the loss is not aware of the risk, the safety incentive is eliminated, not just externalized to another party with a relative disadvantage in reducing accident costs. In fact, putting the loss on a party who is unaware does result in a kind of externalization. If we conclude that pedestrians have a comparative advantage, we must be saying that pedestrians can most cheaply alter their behavior before the accident in order to reduce the costs of that accident. The party with the advantage is "pedestrians who before the accident can change walking habits." They can best choose between the costs of altering their behavior and the cost of bearing the accident losses. But if in practice the burden of automobile-pedestrian accidents is borne by pedestrians who before the accident were unaware of the risk, then the actual lossbearing category is "pedestrians who are hit and had no incentive to alter behavior before the accident.". Under my assumption that accident burdens on actual victims do not affect other potential victims, this is as properly termed an externalization as is what occurs when the ultimate loss-bearing party is society at large rather than pedestrians. 
In effect the decision that pedestrians had the comparative advantage in safety over drivers was based on the assumption that the cost of not looking both ways could efficiently be put on the pedestrian at the time he chose whether or not to look. If, however, that is impossible-if, indeed, the appropriate cost can be put effectively only on a much broader activity, like walking in general or just living-the driver might have the true comparative advantage in safety. This is not because the individual auto driver will bear the burden. He, after all, may also insure. But after insurance the category of driver which bears the loss might have a comparative advantage in safety over the category which will actually bear the loss if the pedestrian is burdened.

Externalization of costs from the party initially held liable to one which does not have a comparative advantage in safety can occur in many ways. I discuss them elsewhere and need not do so here. ${ }^{14} \mathrm{Ex}$ ternalization, to give a few examples, may be caused by strictly economic factors, like the cost of making up various insurance categories; or it may result from political judgments or secondary cost avoidance notions, like a political climate that forbids letting victims be crushed by accidents, and requires their compensation from the national coffers; or it may occur from psychological factors, like the inability of potential victims to view themselves lying dead on a slab, in contrast to the keen ability to foresee oneself injuring another person and being held financially liable for it. However externalization may occur, the probability that accident costs will not rest on the parties initially held liable but will, instead, be externalized to broader categories requires us to make the search for the cheapest cost avoider at all levels where the costs may actually be borne, and not, as the fault system does, at the level of the individual parties involved in the accident. This McKean fails to do in any systematic fashion in his analysis of products liability, and it is this failure that leads him to seem more sympathetic to fault liability than he should be.

A third step in the analysis is reached if we are unable to make a sound decision as to who is the cheapest cost avoider even taking into account the different externalization dangers of alternative allocations of liability. In this case we should allocate accident losses to the best briber, that is, that party who is in the best position to find the cheapest cost avoider and pay him to adopt the optimal mix of avoidance and accident costs. In essence we look for the party who can enter into transactions most cheaply. This assumes that it costs different parties different amounts to enter into transactions, a very likely assumption,

In both cases the group on whom cost incentives are placed is a different one from that initially found to have a comparative safety advantage and is one which clearly does not have such an advantage.

14 See Calabrest, supta note 3, at 144-50. 
and therefore that we maximize our chance of affecting the cheapest cost avoider, given that we cannot identify him collectively, if we charge the party who can find him most cheaply.

For example, in the case of a given consumer product, if we are unable to determine whether the manufacturer, the consumer or some third party is able to reduce accident costs most cheaply, we may nonetheless be able to decide that the manufacturer, say, is in a better position than the other parties to find out who is the cheapest cost avoider and if necessary to bribe the cost avoider to alter his conduct. If that is so, we can place initial liability on the manufacturer and expect that the end result will come closer to the theoretically optimal allocation than if initial liability were placed on some party with higher transaction costs.

One can go on and develop these themes at great length. Specifically, one can point out how both quantitative and qualitative allocation of accident costs to different parties can in many instances lead to cheaper cost avoidance than would the all or nothing allocations of accident costs which occur today and which Professor McKean's analysis seems to accept as inevitable. After all, one party may have a comparative advantage in avoiding one kind of accident cost but not another. And one kind of accident cost, for example, pain and suffering, may be much less easily externalized or undervalued by potential victims than other kinds. Indeed, arguments can be made that if we know neither who has the comparative advantage in safety nor who is the best briber we do better to divide the costs among all the parties involved than to allocate all of them to one party. But such refinements are not my object here. They are necessary to making policy proposals. They are not needed to point out why the policy suggestions McKean may seem to give are not warranted, nor why different products liability situations may justify quite different liability results.

Professor McKean at one point seems to conclude that under manufacturer liability without fault "total costs would increase, because accident prevention would not be produced by those having a comparative advantage in doing so." $15 \mathrm{He}$ also decided, apparently without much empirical investigation, that "[m]ost automobile mishaps involve either driver negligence or plain bad luck rather than defective products ...,"16 and more importantly that it is, in practice, cheaper to

15 McKean text following note 117.

16 McKean text preceding note 119. McKean may at this point in his article be taking a view of "defect" that characterized many early decisions applying strict liability-that is, a view that a product is defective if it fails to conform to its own usual standards or those of other products used for similar purposes. "Defective" here means something like the contract term for breach of the warranty of merchantability.

As McKean recognizes elsewhere in his article, the law has progressed well beyond this 
use market pressures to eliminate negligence than to redesign cars for greater safety. He apparently has also made the same conclusion about all other areas of products liability. It is unlikely that McKean is right if his is meant to be an overall view of automobile accidents, and certain that he is incorrect in assigning the conclusion to all productaccident situations.

The fallacy of focusing on products liability as an entirety rather than on each individual product is shown by a limited examination of three accident situations involved in many products liability casesthe transfusion hepatitis, the cosmetics allergy, and the drug allergic reaction cases. Superficially these examples appear to have many common features. They all involve relatively low incidence of personal physical injury or illness. They all involve purchases by economically weak consumers of products prepared for mass distribution. And they all involve the bodily use of the product with occasional harm. But here the similarities end.

From the number of reported cases we have learned a good deal about the serum hepatitis cases. Courts and juries are agreed that transfusion hepatitis is a statistically predictable event. The disease is contracted when a person is given a blood transfusion containing the hepatitis virus which is undetectable by any known method while it is in the transfusion blood. Blood banks, hospitals and other agencies which prepare blood know that a certain number of transfusions will result in hepatitis, but they are unable to detect or prevent the contraction of the disease. ${ }^{17}$ There seems to be no particular class or group of patients which is especially susceptible. If the virus is in a certain transfusion unit it is almost certain that the recipient will contract hepatitis.

restrictive definition of "defect." There are numerous cases in which a manufacturer has been held liable for damages resulting from product-related injuries without any showing of defects in the manufacturing process or failure to conform to normal working standards or industry expectations. Such defects have come to be called "design defects" but defects they are and liability there is. A trenching machine manufacturer was held liable partly as a result of one witness' testimony that there was a better way to design the machine, although there was extensive testimony that the machine produced was very safe and in no way defective. Williams v. Brown Mfg. Co., 93 Ill. App. 2d 334, 352-59, 236 N.E.2d 125, 135-38 (1968). Indeed the landmark case often pointed to as a turning point in imposing strict liability itself recognized that liability for design defects was completely consistent with the principles there applied. Greenman v. Yuba Power Prods., Inc., 59 Cal. 2d 57, 64, 377 P.2d 897, 901, 27 Cal. Rptr. 697, 701 (1963).

17 Medical change may be as rapid as legal change and may have overtaken us. An economical test, costing perhaps as little as twenty-five cents per pint of blood, which will allow detection of the virus, has apparently been developed. Testing seems to be effective in $25-50 \%$ of the cases. It is almost always correct when it indicates the virus is present, but gives a "false negative" in a substantial number of cases. See Panel of the Committee on Plasma and Plasma Substitutes of the Division of Medical Sciences, National Academy of Sciences-National Research Council, Editorial, 10 Transfusion 1 (1970). See also Washington Star, July 29, 1970, at A9. 
The virus is present in the blood when it is taken from the donor and does not develop spontaneously in the unit after preparation.

On the basis of these known facts we can begin to look for the party with the comparative advantage in reducing accident costs. Initially we shall focus, as have the cases, on the choice between the patient who contracts the disease and the hospital or doctor who administers the transfusion.

First, if we are satisfied that the detection of the virus prior to transfusion is inherently impossible and that there will never be any way to prevent transfusion hepatitis, we are probably justified in concluding that liability rules have no importance for resource allocation. The only concern we are left with is justice and secondary cost avoidance and many argue on either count that it would be wrong to leave the loss on the hapless patient. If we feel that way, we might decide to compensate all such unfortunate souls out of general revenue funds. If, as is more likely, we conclude that there is a possibility that someday a method of detection or prevention is possible, then we are justified in trying to assign initial liability so as to give added incentive to such research.

Assuming then that the resource allocation effects of our decision are to be considered, what happens if the patient is held liable? It would appear that he has one of two choices-to use the blood offered and take the risk of hepatitis or refuse all transfusions. Prior to his need for blood, he is unable to adjust his behavior to reduce the risk of injury except by complete avoidance of the injury-producing situation. Of course he could make the capital investment in a research center for the discovery of a way of preventing hepatitis or alternatively contribute to the local research facility, but we rightly sense that such decisions are far less efficient than those that might be made by the hospital itself..$^{18}$ It is quite unlikely that the potential patient has the comparative advantage at this point.

18 Part of the problem here is that of freeloaders.

The freeloader is the person who refuses to be inoculated against smallpox because the risk of smallpox to him, given the fact that almost everyone else is inoculated, is less than the risk of harm from the inoculation; if enough people are freeloaders it becomes necessary to compel inoculation to avoid smallpox epidemics. He is also the person who refuses to join a union, because the fact that most other workers are union members assures him of the benefits of unionization without the cost. The use of compulsion in these areas suggests that the problem of freeloaders is crucial whenever many people must agree to bear a cost in order to bring about a change favorable to all of them. The problem would not be crucial if nonpayers could be excluded from the benefits of the change, but such exclusion is often extremely expensive. It is precisely that expense which justifies compulsion.

Calabresi, supra note 2, at 437 n.13. Cf. Calabresi, Transaction Costs, Resource Allocation and Liability Rules, 11 J. LAw \& Econ. 67 (1968). 
But this does not mean that the hospital is the optimal loss bearer. On the contrary it may be the case that the supplier of the blood (the blood bank) or the original donor is in a far better position to avoid supplying contaminated blood. Which of these parties is the cheapest cost avoider depends on the facts of the situation.

Between supplier and donor it would depend in part on whether the supplier could discover, relatively cheaply, whether the blood was pure. Even if, in theory, the donor could discover contamination more cheaply than the supplier, the supplier might be a better loss bearer because individual donors might not in practice adequately react to the risk of being held liable because they were judgment proof, insufficiently aware of the risk, or covered by universal liability insurance which did not distinguish in price between those insureds who were prone to be hepatitis-contaminated donors and those who were not. Externalization of costs if donors were held liable might therefore make the supplier or hospital a cheaper cost avoider in practice.

Between a general supplier and a hospital the question of comparative advantage would more likely turn on purely technical facts than on externalization dangers. ${ }^{19}$ If it were impossible or very expensive to prevent hepatitis once the blood was prepared, the supplier would appear to have a comparative advantage. If, on the other hand, the cheapest means of avoidance consisted of some simultaneous injection of chemicals into the blood recipient, then the hospital might be the cheapest cost avoider.

If we did not know what the best method might be, then we might want to place the costs of transfusion hepatitis on some national research center which we guess will have the best chance of finding either some cure or the cheapest avoider to bribe. This could be done directly by "assigning" liability say to the Yale University Medical School, ${ }^{20}$ or indirectly by having the Government pick up the costs and seek a solution through grants financed by the National Institutes

10 This conclusion depends on an assumption that both suppliers and hospitals are equally likely to self-insure or at least purchase insurance which adequately reflects their individual hepatitis-producing potential. Professor McKean impliedly assumes that if consumers were held liable, safety incentives would be maintained either by self-insurance or by insurance plans specifically tailored to each individual's accident potential. He further argues that manufacturer's liability insurance is likely to consist of broad form coverage which lumps all producers in one bag. In fact, just the opposite secms likely. Business insurance tends to be either self-insurance or specially tailored plans, while individual accident insurance tends to reflect uniform clauses covering large categories of persons. See text at pages 88-89 infra.

$20 \mathrm{It}$ is not easy, under the existing legal framework, to find a way of directly assigning liability to a research center that is not connected with the hospital that gave the transfu. sion. Where the party to whom we wish to give an incentive is not directly involved in the accident, we are accustomed to using indirect means like variable taxes or subsidies. 
of Health. There are some disadvantages to each allocation, but what seems clear is that the last person whom we would want to see bear the costs is the individual patient who is unlucky enough to get the bad blood.

The situation of allergic reactions to cosmetics is as frequently litigated, often with the same results as in the transfusion hepatitis cases. Patients are usually held liable on a theory of not burdening health care. Women whose hair has fallen out are often required to bear the loss on theories of "allergic reaction" or "idiosyncratic sensitivity." In this case, unlike the situation in transfusion hepatitis, the end result may be desirable on resource allocation grounds.

The cosmetic reaction cases can conveniently be divided into two types-those in which injury occurs to almost every user due to normal body reactions against certain chemical compounds, and those in which the normal body does not react but certain particularly susceptible individuals do. The first class is perhaps economically identical to the transfusion hepatitis cases while the second class serves as a convenient contrast.

In most cases of cosmetic allergic reactions it is possible to detect the sensitivity before using the product. This could often be accomplished by using test patches similar to the tuberculin patches used to detect tuberculosis. In other cases the allergic reaction appears slowly with continued use, initially as a redness which becomes more irritated with further use. In either event the individual is in a position to detect the risk by some means before serious harm occurs. Because of the innumerable number of allergenic compounds which may be present in any given cosmetic combination, the manufacturer may not be in any position to predict even the aggregate number of allergic responses, much less the probability that any given individual will suffer. In such a situation it would appear that the user does possess a comparative advantage in avoiding the accident, at least once the manufacturer is held responsible for warning users of possible allergic reactions. Who has a comparative advantage in providing for a patch test might, however, be a separate question, the answer to which depends in part on how likely it is that allergic users will know that they may be the odd person who is allergic. (In contrast the manufacturer knows both more and less, for as to him the occurrence of the allergy may be a statistical certainty; but he has no inkling of whom it will hit.) It will also depend on how expensive it is for individuals to get a patch test if the manufacturer does not supply the patch, and how expensive it is to provide a patch for every user as against testing only those who suspect they may be allergic. 
Drug allergic reaction cases are somewhere in between the other two. Unlike the hepatitis victim, the woman who is likely to suffer a thrombosis from using birth control pills is an idiosyncratic individual. But unlike the cosmetic cases there is no cheap way of having her test herself for the idiosyncrasy. The damage, moreover, is likely to occur all at once so that there is little chance for the potential victim to become especially aware of the risk as she begins using the drug. Nevertheless, the individual may have more knowledge than the drug company that birth control pills are somewhat more of a risk for her than for others. She may, for example, have a history of thrombophlebitis or other blood disorder. The comparative advantage in these cases would depend on whether the likelihood that some could individualize their high risk potential was great enough to overcome the fact that most could not or would not in practice do so. To the extent that potential victims could not individualize their greater risk, the cheapest cost avoidance would probably lie in the development of a compound that did not have the danger or in a test to indicate who was susceptible. As to both of these the drug company would clearly be in the best position to balance the cost of developing the avoidance devices against the cost of paying for the losses brought about by the existing drug. To the extent users would not individualize their risk because of a tendency to disregard warnings or contraindications addressed to the general public but could be encouraged to do so by expert advice and prescription requirements, the prescribing physician might be the cheapest cost avoider.

It is by no means crucial to the present argument to accept the ultimate factual validity of any of these three analyses. What is important is to see that optimal resource allocation does not require the same liability rule in all product-accident situations. The transfusion hepatitis, cosmetic reaction and drug allergy cases alone indicate that quite different liability decisions may be necessary in different product situations. There is an inherently dangerous temptation to generalize from one product to another, thereby oversimplifying and erroneously assigning liability in some situations.

Not only do I disagree with Professor McKean's tendency to consider products liability rules in general without analysis of specific product-accident situations, I question his implication that in most situations economic theory points to consumer liability plus some fault-based manufacturer liability. Indeed, it appears to me that, to the extent general conclusions about products liability are useful, economic theory indicates that consumers do not in practice have a comparative advantage in safety. 
If consumers were held liable for most product-related accident costs and they purchased some form of product-accident insurance it is quite likely that the costs of knowing the accident proneness of different consumers and of making insurance categories on that basis is such that consumers with substantially different accident potentials would be lumped into one category. The relatively small degree of differentiation in automobile liability insurance where differentiation should be relatively easy certainly points that way. In fact, it might not even be economical to distinguish between product-related accidents and those other losses, like ulcers, which are by-products of our modern society. If the comparative advantage lay in altering patterns of consumer behavior rather than in discouraging use by certain classes of consumers, insurance might not be able to allocate the costs properly at all. Consumer liability with insurance therefore entails a high possibility of externalization of safety incentives. If the manufacturer were held liable, however, he would be more likely to self-insure by saving or have commercial insurance more closely drawn to fit his particular accident record.

If consumers were held liable and were forbidden from insuring in order to diminish the likelihood of externalization to broader insurance categories, another form of externalization would probably occur as a result of inadequate risk awareness. Assuming that the consumer does in fact have a comparative safety advantage, that advantage is meaningless unless he adequately appreciates the risk he faces.

The first condition for this awareness is adequate information and this may be very costly. Even where information is available, it may be in the form of masses of technical data that are extremely difficult or costly to comprehend. The two primary sources of information as to accident potential in products liability situations are consumers and manufacturers. Consumers as individuals are unlikely to acquire adequate information on product dangers from personal experience since for a given individual the likelihood of multiple incidents of product-related accidents is small. Nor are they likely to inform other consumers adequately because of the unorganized nature of the group. Manufacturers, on the other hand, are not particularly inclined to publish statistics and information concerning the accident potential of their products, and governmental coercion to supply such information is of questionable efficacy. The cigarette-filter-cancer controversy is eloquent testimony of the difficulty of informing consumers.

The second condition is that consumers adequately evaluate the risks when they are informed of the dangers. Most of us tend to underevaluate the likelihood of our own involvement in an accident how- 
ever compelling the statistics. Accidents happen to the other guy-I'm careful or lucky. This attitude seems to be especially true when the accident involves serious personal injury. The effect of such psychological underevaluation is to reduce seriously the incentives to alter behavior. It seems likely that the manufacturer can view the situation more objectively and more fully appreciate the risks involved.

Such externalization potentials throw considerable doubt on the suggestion that consumer liability can lead to proper allocation, even assuming that at first glance consumers have a comparative advantage. Having made this argument I again emphasize that the effects of products liability rules cannot satisfactorily be analyzed without close examination of the particular product-accident situation involved. The externalization factors discussed here are as subject to individual variations as the comparative safety advantages discussed earlier. Both are guidelines for consideration not indications of the likely results of analysis.

This caveat does not mean that each injury case should be decided on its own bottom. Quite the contrary, the administrative costs of such case-by-case decision making are almost certainly not worth the added accuracy in terms of finding the cheapest cost avoider. In addition, as I indicated in discussing the fault system in the Journal of Law and Contemporary Problems and in The Costs of Accidents, case-by-case determinations tend to introduce errors, because they tend to ignore the dangers of externalization and to compare the cost avoidance potentials of only the parties immediately involved. Thus, to criticize Professor McKean for overgeneralizing does not compel case-by-case decisions. It does suggest, however, that there is no one simple rule that we can apply to find the cheapest cost avoider for all types of accidents in all types of product situations. How far one should in practice distinguish different product situations will depend on how expensive such analysis is and how likely it is to lead to significantly cheaper cost avoidance. ${ }^{21}$

It will also depend on how important we believe market deterrence of accident costs is. Throughout this critique I have followed Professor McKean's lead and assumed a very substantial role for market deterrence of accident costs. As McKean well recognizes, this need not be so. To the extent we are concerned with secondary cost avoidance, nice

21 In $\mathrm{my}$ book I call this choice between the costs of administering a particular system of accident law and the effectiveness of the system "tertiary cost avoidance." The meaning and interrelations between tertiary cost avoidance, secondary cost avoidance, primary cost avoidance (which I divide into collective and market methods of control) and justice are the principal themes of the book. 
distinctions between the comparative advantage in safety a drug manufacturer may have as against the users may become insignificant. This is not to say that we should ignore primary accident cost avoidance. It only means that where the case in terms of primary cost avoidance is close we will opt for the loss allocation which effectuates significant secondary cost reductions. Thus, the existence of other goals may at times make the decision as to who should be held liable easier.

At other times it may make matters more complex. The market is not the only device we can use to make primary accident cost avoidance decisions. We can also decide collectively that certain acts or activities are to be banned regardless of their market desirability. The availability of collective controls may at times simplify, but.may also at times render harder, decisions as to comparative advantage in producing safety. For instance, in the earlier example of auto manufacturer versus driver liability we saw that driver liability made easier those choices between paying accident costs and altering behavior of drivers. Conversely, we saw that manufacturer liability made easier those choices which went to how cars are made. In the absence of collective controls we had to choose which of the choices between accident costs and avoidance costs we wished our liability system to highlight. Transaction costs, we assumed, made it impossible to highlight both. The existence of collective controls enables us to affect relatively cheaply some of those decisions which our choice of liability rules made too expensive for the market to affect. Thus it is not surprising that we require seat belts, given that our liability system today makes a market choice for or against seat belts difficult. But the existence of collective controls means that in choosing a liability rule we must not only seek to determine who has the comparative advantage in producing safety and hold him liable, we must also decide which choices we can with greater advantage control by collective fiat and which we can best leave to the market. If we wish to forbid driving by certain categories of accidentprone people for moral, political or efficiency reasons, it may be that given those prohibitions manufacturers have the comparative advantage in safety, even if absent the prohibitions drivers would.

A full exposition of the complex relationship between collective and market controls requires a discussion of book length rather than an article like Professor McKean's or a critique like this. And the complexities of the relationship may make us despair of making intelligent choices. But that ought not to be the conclusion either to that discussion or to this paper. We are, in fact, making such choices quite unintelligently all the time in accident law. We are making choices without even asking the right questions, as is indicated by the disturbing ten- 
dency in products liability cases to look simply for the best loss spreader as if that were the only goal of accident law, and by the inclination to resort to collective fiat to accomplish primary accident cost reduction.

I do not expect that we are ever likely to come up with empirical data sufficient to give us complete answers to the right questions. But that need not lead to inaction. After all, lawyers and legislators, unlike theoretical economists, must guess all the time. And it is precisely the function of good government to make intelligent guesses. As lawyers and economists we must see that the right questions are asked and that whatever data is available which helps answer the questions is sorted out. Analyses like Professor McKean's, tentative and incomplete though they may be, are crucial first steps toward asking the right questions. Taken as that they are very valuable indeed. 